\title{
System Scenario Selection Method for Faster Analysis
}

\author{
Timothy L.J. Ferris \\ Centre for Systems Engineering, Cranfield \\ University, Defence Academy of the \\ United Kingdom Shrivenham, SN6 8LA \\ Timothy.ferris@cranfield.ac.uk
}

\author{
Stephen Barker \\ Centre for Systems Engineering, Cranfield \\ University, Defence Academy of the \\ United Kingdom Shrivenham, SN6 8LA \\ s.g.barker@cranfield.ac.uk
}

\begin{abstract}
Scenario analysis is a frequently-used method to explore what a proposed system is required to do in the early phases of system development leading towards finding system requirements. A system which is intended to perform a variety of roles under a range of conditions is likely to result in the need for a quantity of scenarios that becomes intractably pluriform. The consequence of too many scenarios is that either the number of scenarios to be analyzed must be reduced to a manageable number or the analysis is likely to be perfunctory, diminishing the value of the analysis, or the total effort required for the analyses may become unjustifiably great given the value of the project and the risks associated with it. We present a method for reducing the number of scenarios to be analyzed through study of the organization of the factors which distinguish scenarios from each other, and for selecting which scenarios need analysis through identifying their points of commonality and identifying where differences may impact system capability. Our method organizes the types and potential values of factors related to a particular system development in order to reduce the number of scenarios to be investigated. We illustrate our approach with a simple case developed for the purpose of this paper.
\end{abstract}

\section{Introduction}

Scenarios are described by Carroll (2000) as 'stories about use', which incorporate stories about people and their activities. Analysis of such scenarios is a frequently-used method in the exploration of what a proposed system or systemic intervention is required to do, and has its roots, as far back as the 1960s, in the need to generate better forecasting techniques (Huss, 1988). Normally applied in the early phases of the systems work, scenario planning and analysis can provide rich and detailed insights into potential future options (Wang and Lan, 2007), and although authors such as Porter et al. (1991) have suggested that it is less precise a process than forecasting, the method is vital - Brooks (1987) states that "no other part of the work so cripples the resulting system if done wrong" - and has many benefits, including serving to 'tame requirements' (Hsia et al, 1994), reduce risk (Clemons, 1995) and deal with the uncertainties surrounding future decision-making (Postma and Liebl, 2005). Such analysis involves the description and exploration of a range of situations in which the system under consideration is likely to be employed, describing the task outcomes required and the 
conditions under which those outcomes are required. Typically, scenarios are suited to an uncertain environment where there is scarcity of data, and a number of vague or unquantifiable factors pertaining to the system under study (Huss, 1988). During scenario analysis the timeline of events and actions necessary for the performance of each scenario will be story-boarded with description of what must happen along with a statement of measures of performance for each salient feature of the scenario.

The level of development of scenarios may vary with both the lifecycle phase of the system development project and with the judgement of the impact of possible findings. Thus, scenario development is likely to be rudimentary at earlier stages of the systems project as broad-brush scenario development is done, to map out the major issues. Later, the work is likely to be developed in greater detail so that it becomes clear what the actions and necessary performance to enable the identified tasks to be performed are. Similarly, for a product or system for which the impact of failure or poor performance are minor, the scenario work can be truncated with low risk. However, if the likelihood of system failure to provide the required service under all the relevant conditions is high, then it is necessary to investigate each scenario thoroughly and to use a systematic process to identify all the scenarios. In practice most systemic interventions are between the extremes, and therefore require significant scenario development to ensure that the intended effect of the system is well understood, but also that sufficient, but not excessive, scenarios are developed sufficiently to provide insight about the proposed system without demanding excessive work.

This paper describes a concept for reducing the effort required to perform scenario analysis which is still under development, with the next stage to develop an example which clearly shows the method and enables demonstration of the elements, strengths and characteristics of situations for which the method is suitable.

\section{Purpose of Scenario Planning and Analysis}

Scenario planning and analysis has been used in a wide range of fields, such as: user-centered design (Bodker, 2000; Blythe and Wright, 2006), software reliability analysis (Yoacoub et al, 1999), power management problem identification (Growe-Kuska et al, 2003), wastewater treatment decision-making (Kalbar et al, 2012), selection of investment projects (Liesiö and Salo, 2012), and coastal planning for climate change (Tompkins et al, 2008). Outside of what might be characterized as commercial and business decision-making, scenarios are increasingly used in education, in areas such as case-based learning (Thistlethwaite et al, 2012), and problem-based learning (Eshach and Bitterman, 2003; Hmelo-Silver, 2004). The purpose of scenario planning and analysis is to identify the range of issues which the system may confront during its future or service life and to reduce uncertainty (Shoemaker, 1995). It is essential, whatever the application, that the scenario be sufficiently that it is clear what the intended performance needs to be in order to provide 'adequate' results. When considering the purpose of scenario work, Bradfield et al (2005) identify four main areas of purpose, which are: making sense of a particular puzzling situation, developing strategy, anticipation, and adaptive organizational learning. In this, it might be seen that two characteristics are important:

1. System and environmental state; and

2. The action to be done by and to the system.

The combination of these characteristics describes what must be achieved by the system under what conditions. These elements of what the system must be and do are the essential characteristics in order to define what constitutes a suitable system for its purpose. Huss (1988) develops this argument 
by stating that the purpose of scenario analysis is to span the gap between forecasting and planning as described in Table 1.

\section{Toward a General Framework for Scenario Analysis}

Scenario analysis has been impeded by the lack of a systematic way to analyze and generate suitable cases and scenarios (Hsia et al., 1994). The fundamental challenge is that whilst it is obvious that an efficient path through the exploration of scenarios is desirable, it is also necessary to ensure that the path chosen is effective, that is that it does not leave the engineer vulnerable to flaws in the system concept or design to be introduced as a result of insufficient knowledge and appreciation of what is required of the system (Chermack, 2004). It is also important that the process considers as much different information, gathered using potentially differing requirements elicitations methods, as is necessary to fully encompass the nature of the task (Diaper, 2001). Therefore, the need exists for a method to choose an efficient set of scenarios that results in identification of all of the scenario elements to enable planning of the system without risk of omissions arising from investigation of too few scenarios.

\begin{tabular}{|l|l|}
\hline Emphasize market and customer orientation & Building team spirit and consensus \\
\hline Promoting a long-range perspective & Identifying novel and diverse ideas \\
\hline Providing insight into business dynamics & Facilitate sensitivity analysis \\
\hline $\begin{array}{l}\text { Incorporating qualitative input into the } \\
\text { forecasting process }\end{array}$ & Encourage contingency planning \\
\hline $\begin{array}{l}\text { Documenting implicit assumptions, biases, } \\
\text { and values }\end{array}$ & $\begin{array}{l}\text { Provide an early warning system (of } \\
\text { future disruptive events }\end{array}$ \\
\hline Encouraging intra corporate communications & \\
\hline
\end{tabular}

Table 1. Purposes of Scenario Analysis, abridged from Huss (1988)

In order to attempt to resolve this, we are aiming to achieve an approach to the simplification of the scenario analysis activity which provides a general framework. Such a framework must formulate the problem in an abstracted general form rather than as a set of specific factors, methods and relationships which are presented as a template to fit all cases. A general framework will need to be tailored to fit what is relevant to the specific system under consideration, which with the broad range of systems possible could be any of a wide variety of possible sets of characteristics, some of which will be relevant only in particular cases, and some relevant over a broad range of classes, but few, if any, would be relevant in all cases. The scenario analysis for a system must account for the two sets of factors:

1. The system and environment state conditions.

2. The system function and performance levels.

Each of these types of factors may have a plurality of values. For example, a system which is intended to operate with full performance under some range of environmental conditions may also be expected to operate with defined levels of degradation over a further, extended, range of environmental 
conditions outside the 'full operation' range. Similarly, the scenarios must include consideration of resilience, and so scenarios should include defining acceptable systems behavior under various classes of degradation caused by threat events (Jackson, Cook, Ferris, 2015).

\section{Scenario Construction}

Huss (1988) suggests that scenarios can be classified into three types: intuitive logic, trend analysis, and cross-impact analysis. In each case, the scenarios need to consider:

1. What must be done: the transformation or path between the initial state and target event (Kahneman and Tversky (1982); and

2. The conditions, such as environmental constraints, under which the effect must be achieved.

The tasks described as 'what must be done' are Requirements expressed by the stakeholders. As such these tasks refer to whole things that must be achieved, such as shipping some quantity and type of goods from one type of site to another under certain conditions. It may be appropriate to describe the task performance objectives, such as how much, or how fast, etc, in a trade-space associated with the potentially constraining operational conditions. That is, under desirable operating conditions it may be appropriate to demand on level of performance but under more difficult conditions, it may be recognized as acceptable to demand only a reduced level of performance. The decision to permit a trade-space involving performance levels demanded of the system and the conditions may, for many systems, be a very important factor in enabling a solution space that affords more options for solutions and which has at least some available options that are significantly cheaper than if all performance demands are treated as absolute under all conditions. This process of scenario generation has been codified into a number of steps by various authors, examples being the eight-step SRI approach described by Ogilvy and Mancle (1984), subsequently simplified into a four-stage approach by Shin et al (2011). Both of these example approaches are given at Table 2.

\section{Identifying and Developing Individual Scenarios}

It is common to find that the scenarios identified may appear to be variations of each other which suggests a strong analogy between the primary scenario and the secondary scenarios. For example, a base vehicle might be used as a goods carrying vehicle with one internal fit and as an ambulance, with a different internal fit. The analogy is that the patient and other medical equipment is, from the viewpoint of stuff to be shifted, analogous to goods to be shipped. However, these scenarios may make different demands on some characteristics of the system, in this example the ride quality where what is acceptable for one use may not be acceptable for another. It is therefore extremely important that the task of analysis such scenarios is iterative (Diaper, 1998) so that no information is lost, not fully understood, or simply missed altogether.

Other scenarios relevant to understanding what the system needs to be and do include scenarios of potential extension uses, where a user, in the absence of a purpose built system may choose to build on the analogy of the affordances of the current system and their desired capability to deploy the system for an off-label purpose. And there are further scenarios to address other necessary tasks including, potentially, tasks such as maintenance, installation and commissioning etc.

To determine which scenarios need to be developed we propose the development of a table describing possible scenarios of the form of Table 3. In abstract form, as presented in Table 3 this appears simple with performing a particular system task under a set of conditions. However, the condition set may be multiple for each system task, that is, each task may be needed under each of several sets of conditions. A 'system task' is a complete action performed by or on the system which is most likely to be a compound of a number of smaller activities. Given that there may be a significant set of tasks to be 
performed and that each of the tasks may be required under a number of conditions the number of scenarios may be large. However, many of the scenarios are likely to have considerable similarity to other scenarios. Therefore, analysis of the full set of scenarios is likely to produce considerable work with substantial overlap. In particular, note that Table 3 anticipates that a system may be expected to perform the same tasks under a range of conditions, each of which is represented by a distinct scenario. These scenarios are distinct because it is plausible that design requirements for the system to perform the task under each of the condition sets may be different.

\begin{tabular}{|c|c|}
\hline $\begin{array}{l}\text { Eight-step SRI approach } \\
\text { (Ogilvy and Mancle, 1984) }\end{array}$ & $\begin{array}{l}\text { Four-stage Approach } \\
\text { (Shin et al, 2011) }\end{array}$ \\
\hline 1. Analyzing decisions and strategic concerns & 1. Identifying the key decision factors \\
\hline 2. Identifying the key decision factors & $\begin{array}{l}\text { 2. Identifying and analyzing the key } \\
\text { environmental factors }\end{array}$ \\
\hline 3. Identifying the key environmental forces & 3. Defining scenarios \\
\hline 4. Analyzing the environmental forces & $\begin{array}{l}\text { 4. Analyzing implications for key } \\
\text { decision factors. }\end{array}$ \\
\hline 5. Defining Scenario Logistics & \\
\hline 6. Elaborating the scenarios & \\
\hline $\begin{array}{l}\text { 7. Analyzing implications for key decision } \\
\text { factors }\end{array}$ & \\
\hline $\begin{array}{l}\text { 8. Analyzing implications for decision } \\
\text { strategies }\end{array}$ & \\
\hline
\end{tabular}

Table 2. Examples of approaches to Scenario Generation.

\begin{tabular}{|l|l|l|l|}
\hline ID & \multicolumn{1}{|c|}{ Scenario Name } & \multicolumn{1}{|c|}{ System Task } & \multicolumn{1}{|c|}{ Conditions of Scenario } \\
\hline 1 & Scenario Name 1 & System Task 1 & Condition set 1 \\
\cline { 1 - 1 } 2 & Scenario Name 2 & & Condition set 2 \\
\hline 3 & Scenario Name 3 & System Task 2 & Condition set 3 \\
\cline { 1 - 1 } 4 & Scenario Name 4 & & Condition set 4 \\
\hline 5 & $\ldots$ & $\ldots$ & $\ldots$ \\
\hline
\end{tabular}

Table 3. Itemization of possible scenarios

We need now to find a method to simplify the set of scenarios to be analyzed. This task can be performed by identification of the action sequence required to perform the system task which 
constitutes the action of the scenario. Since the task must be performed under some set of conditions, as identified previously, Table 3 , it is necessary to capture the information of the conditions under which the actions will be performed within each scenario, Table 4. Note that in Table 4, between each pair of labels for Actions, e.g. Action 1 and Action 2, there is an additional action name of the form of "Transition Action $x$ to Action $y$ ". This is included here to explicitly emphasize that the Actions which are most likely to be thought of by scenario describers whose focus is on the capability provided by the system are the large scale actions which are clearly part of the purpose of the system. However, the transition from one state of the system, associated with the previous and later actions, must be considered, and if not considered appropriately could be the cause of accidents. (For example, accidents which occur during processes such as loading or unloading vehicles, or during construction works, when the action is associated with potential instability of the platform on which it is being performed.) Calling out the concept of transition between the larger actions causes attention to be put on making appropriate consideration for the impact of the various transition actions which are required between task achieving actions. Explicit identification of the transitions is also helpful in the next stage of using this approach.

At this stage we have identified a large range of scenarios, associated with achievement of some set of system level tasks to be achieved under a group of sets of conditions, Table 3. This list of scenarios is potentially large. Since the system level tasks require performance of the particular activities and transitions under all of the sets of conditions, the application of the simplification of Table 4 has reduced the number of scenarios to be developed to only one for each of the system level tasks. In the expansion we cannot use the idea of "worst case" conditions, because each condition set is a set of conditions which are in different dimensions which could interact with the proposed system in complex ways that do not make any condition set necessarily the worst case.

\begin{tabular}{|c|c|c|c|}
\hline ID & System Task & $\begin{array}{c}\text { Actions Performed BY or ON the } \\
\text { System (in Order) }\end{array}$ & Condition Sets for the Action \\
\hline 1 & System Task 1 & Action 1 & Condition sets $1,2,4$ \\
\hline 2 & & Transition Action 1 to Action 2 & $\ldots$ \\
\hline 3 & & Action 2 & $\ldots$ \\
\hline 4 & & Transition Action 2 to Action 3 & $\ldots$ \\
\hline 5 & & Action 3 & $\ldots$ \\
\hline 6 & & $\ldots$ & $\ldots$ \\
\hline 7 & $\cdots$ & $\ldots$ & $\ldots$ \\
\hline
\end{tabular}

Table 4. Itemization of action sets demanded by each scenario and the conditions sets under which the actions are required.

However, at the stage of Table 4 we may have another opportunity for simplification of the scenario work. Each scenario comprises a sequence of actions and transitions, each identified as the atomistic tasks to be achieved. It is likely that there is duplication of actions and transitions between various 
system tasks and groups of condition sets. Therefore, the analysis for each action or transition can be done once in order to determine the system or lower level requirements arising from the scenarios.

\section{Example: Military Sea to Land Shipping System}

We use an example as a means to illustrate our approach. The example is of a military system with the purpose of shipping cargo from a ship at sea, near the coast, to land sites including a land base and a forward support delivery point. The loads this system needs to transfer have a significant maximum mass and maximum volume. The system needs to be specified with quantitative levels of performance to be achieved under defined conditions. A further question is whether personnel might be the load, that is that the system may be used as a routine personnel transport means or possible only in emergency events. We develop this example through the set of steps described by Shin et al (2011), Table 2.

\section{Example Step 1: Identifying the key decision factors}

Shin et al (2011) provide identification of the key decision factors as the first step in system scenario analysis. This activity could be done in various ways. We have chosen to use a rich picture to identify the key decision factors, following Checkland (1981). Our rich picture is shown in Figure 1. The rich picture shows to mechanisms of transport, the ship-to-shore element being pictured as an aircraft, and the land-to-land element as an armored road convoy. Evaluation of the rich picture will raise the question: was one or two type of equipment item envisaged as the means to provide the solution? This question can be left in abeyance for the time-being since many of the issues to be elaborated in the scenario discussions that follow are common to all solutions, and the answers found may assist the decision about the appropriate solution approach.

\section{Example Step 2: Identifying and analyzing the key environmental factors}

In Table 5 we identify a set of factors and conditions which describe potential operational conditions which, in turn, are the descriptors of acceptability of the system. This step is important because it specifies conditions under which the system must perform and measures of performance required under those conditions. The combination of conditions and measures of performance is a step towards defining some of the system requirement measures of effectiveness.

Clearly Table 5 is a rudimentary description of factors and levels of attainment desired in scenarios, where the gradation in several fields in the 'Level of Attainment' column indicates scenario relevant information, that is, that under certain conditions one level of performance is acceptable and under other conditions a different level of attainment. This information is a saimple implementation of the value of achieving particular measures of performance which is used to inform some trade-space decision processes.

\section{Example Step 3: Defining scenarios}

Scenarios concern some mission to be performed by the system under defined conditions. That is, the system must be capable of performing a certain task under defined conditions. Except in very simple situations the tasks demanded by a scenario will require a storyboard of a sequence of actions to be performed where each will need to be performed under particular conditions to levels of performance which may be specified in a conditions independent or conditions dependent manner. The levels of attainment described in Table 5 are directly linked to any condition dependence criteria described in the scenarios. 


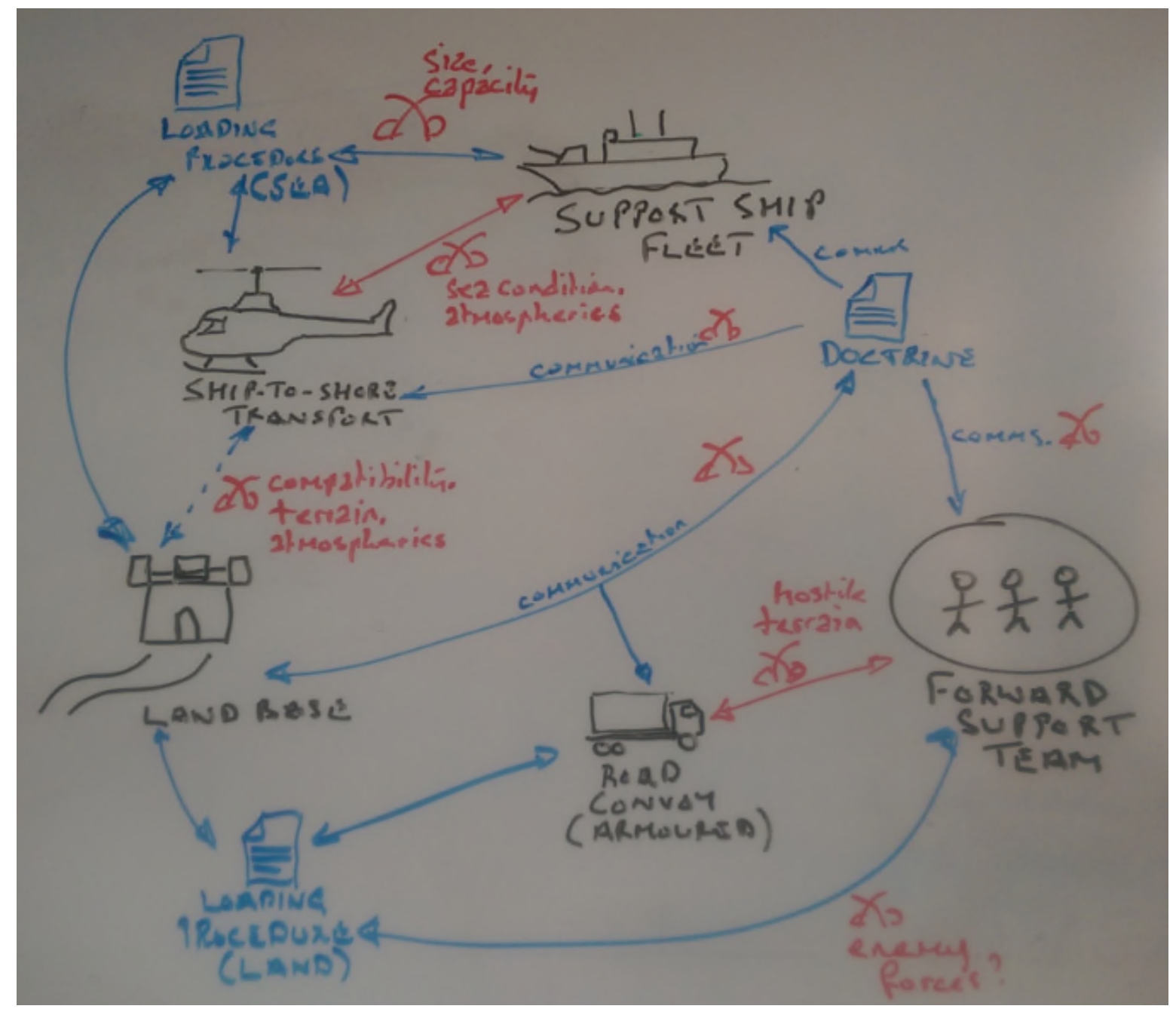

Figure 1. Rich picture of the sea to land transport system.

\section{Example Step 4: Analyzing implications for key decision factors}

In Table 6 we expand some of the scenarios that assist in describing the intended functionality of the system. It is only necessary to expand part of the set of possible scenarios in Table 6 here because our purpose is to illustrate our method, not to fully specify the example system.

In Table 7 we develop one of the system tasks in Table 6 into a series of actions to be performed by the system, which in combination, when done in the right order, enable completion of the system task. Each action must be performed under the conditions which apply for the system task.

It is plausible that some system tasks may, in terms of the overall action required differ only because of the conditions under which the task is to be done. For example, the system task "shipping materiel from ship at sea to land base" is identified in Table 6 as associated with two scenario names, scenarios 1 and 2, which differ, at this level, only in the conditions under which the scenario is performed. Various approaches can be taken to this issue, with the appropriate approach depending on the specifics of the system context. One may take the view that all shipping will be done in a manner 


\begin{tabular}{|c|c|c|c|}
\hline Number & Factor Type & Specified Item & Required level of attainment \\
\hline 1 & $\begin{array}{l}\text { Environment } \\
\text { state }\end{array}$ & $\begin{array}{l}\text { Ambient temperature } \\
\text { during operation }\end{array}$ & $\begin{array}{l}\text { Normal operation: } x \leq T \leq y \\
\text { Extended operation: } T<x \text { and } y<T\end{array}$ \\
\hline 2 & $\begin{array}{l}\text { Environment } \\
\text { state }\end{array}$ & $\begin{array}{l}\text { Sea state: WMO Sea } \\
\text { State Code }\end{array}$ & $\begin{array}{l}\text { WMO State }<4 \text { full operation, no precautions } \\
\text { WMO State }<6 \text { full operation, protection } \\
\text { precautions active } \\
\text { WMO State }>6 \text { can survive, protection } \\
\text { precautions active }\end{array}$ \\
\hline 3 & $\begin{array}{l}\text { Environment } \\
\text { state }\end{array}$ & Ground bogginess & $\begin{array}{l}\text { This need a measure of the resistance of the } \\
\text { ground to vehicle bogging }\end{array}$ \\
\hline 4 & $\begin{array}{l}\text { Environment } \\
\text { state }\end{array}$ & $\begin{array}{l}\text { Cross-country } \\
\text { vegetation } \\
\text { penetration }\end{array}$ & $\begin{array}{l}\text { This needs a measure of the density of } \\
\text { vegetation which can be driven through }\end{array}$ \\
\hline 5 & System state & $\begin{array}{l}\text { All subsystems } \\
\text { function }\end{array}$ & Full operational performance \\
\hline 6 & System state & $\begin{array}{l}\text { Communications } \\
\text { subsystem } \\
\text { nonfunctional }\end{array}$ & $\begin{array}{l}\text { Defined autonomous function plan allows safe, } \\
\text { partial function }\end{array}$ \\
\hline 7 & Performance & $\begin{array}{l}\text { Load carrying } \\
\text { capacity }\end{array}$ & Load described in mass and dimensions \\
\hline 8 & Performance & Speed of movement & $\begin{array}{l}\text { Described as linear speed at WMO particular sea } \\
\text { state measures }\end{array}$ \\
\hline 9 & Protection & $\begin{array}{l}\text { Resistance to fire and } \\
\text { other attacks }\end{array}$ & $\begin{array}{l}\text { This needs a specification of the types of } \\
\text { in-coming that the armor can resist }\end{array}$ \\
\hline
\end{tabular}

Table 5. System factors associated with the definition of scenarios. Note, these factors are presented here as examples; each system needs specific investigation to determine which factors are relevant, and the appropriate level of attainment for each.

which can cope with the greater challenges of the Sea state 4 condition. But this is likely to impose load limitations and additional protection activities which significantly reduce the cargo transfer capability per load and increase the time to carry each load. Therefore, it may be appropriate to modify the operational procedures to make two distinct scenarios to perform the same kind of task under different conditions. In the atomization of the system task into activities developed in Table 7 there are several tasks which appear the same, or activities which may appear "easier" in one scenario than the other. In the goal to accelerate the analysis process it is tempting to believe that the analysis problem can be reduced by simply analyzing the hardest equivalent case. But this raises the question: what is the hardest case? Consideration must be given to the differences which could appear between scenarios to determine in which scenario the action which performs the equivalent role is the more 
challenging. The determining factor may be a general fact related to the scenario, so in this case the problems of dealing with a rough sea state are likely to be the most challenging factor and therefore demand the rough sea condition be analyzed. However, it is possible, that in some cases the greater challenge for certain tasks may come from one scenario and for another task from another scenario. In this case only the more challenging conditions for the task need be investigated, unless, in the system solution proposed it is considered appropriate to implement the task with some kind of variation that demands independent investigation.

\begin{tabular}{|c|c|c|c|}
\hline ID & Scenario Name & System Task & Conditions of Scenario \\
\hline 1 & Ship sea-land calm & \multirow{2}{*}{$\begin{array}{l}\text { Shipping materiel from } \\
\text { ship at sea to land base }\end{array}$} & Calm sea \\
\hline 2 & Ship sea-land rough & & Sea state 4 \\
\hline 3 & Ship land-land clear & \multirow{2}{*}{$\begin{array}{l}\text { Shipping materiel from } \\
\text { land base to forward } \\
\text { position - on road }\end{array}$} & No opposition anticipated \\
\hline 4 & Ship land-land opposed & & Opposition expected \\
\hline 5 & $\begin{array}{l}\text { Ship land-land } \\
\text { cross-country opposed }\end{array}$ & $\begin{array}{l}\text { Shipping materiel from } \\
\text { land base to forward } \\
\text { position - cross-country }\end{array}$ & $\begin{array}{l}\text { Route includes areas } \\
\text { where boggy conditions } \\
\text { are expected. } \\
\text { Opposition expected. }\end{array}$ \\
\hline 6 & $\begin{array}{l}\text { Ship land-land vegetation } \\
\text { opposed }\end{array}$ & & $\begin{array}{l}\text { Route through thick } \\
\text { vegetation. } \\
\text { Opposition expected. }\end{array}$ \\
\hline$\ldots$ & $\ldots$ & $\ldots$ & $\ldots$ \\
\hline
\end{tabular}

Table 6. Itemization of possible scenarios

The more important factor to identify is where 'actions' appear in multiple scenarios. The unit of investigation should be the 'action', not the 'scenario'. Analysis at the level of 'scenario' would result in multiple analysis of the same 'tasks' under, possibly, the same conditions as parts of scenarios differentiated over other details. Whilst, in some cases, particularly where the risks associated with system failure, either to perform correctly or of safety, are high it may be appropriate to exhaustively analyze each scenario even where it appears there are similar 'tasks' to be performed, in most, lower risk systems it is desirable to reduce the analysis work. Reduction of the analysis by reducing the unit of analysis in the scenario analysis to the 'task' reduces the work required to discover the system requirements developed through the scenario analysis.

\section{Conclusions}

The scenario analysis approach described here can be used to reduce the work of analyzing scenarios through identifying the elements of actions, devolved to their constituent tasks, and the conditions under which they must be achieved. Achievement of the scenarios, each of which requires performing a particular system action, and where each action is composed of a set of tasks, is demanded by the 
contribution that the system is required to make in its intended context of deployment. Our approach to decomposing the scenario analysis to the level of atomized tasks, each of which may be a constituent of multiple scenarios, enables a reduction of the effort required in the scenario analysis.

\begin{tabular}{|c|c|c|c|}
\hline ID & System Task & $\begin{array}{l}\text { Actions Performed BY or } \\
\text { ON the System (in Order) }\end{array}$ & $\begin{array}{l}\text { Condition Sets for the } \\
\text { Action }\end{array}$ \\
\hline 1 & $\begin{array}{l}\text { Shipping materiel from } \\
\text { ship at sea to land base }\end{array}$ & $\begin{array}{l}\text { Open the conveyance } \\
\text { 'vehicle' to enable loading }\end{array}$ & Sea state 4 \\
\hline 2 & & $\begin{array}{l}\text { Load the cargo into/onto } \\
\text { the conveyance 'vehicle' }\end{array}$ & Sea state 4 \\
\hline 3 & & $\begin{array}{l}\text { Close the conveyance } \\
\text { 'vehicle' to enable travel }\end{array}$ & Sea state 4 \\
\hline 4 & & $\begin{array}{l}\text { Initialize the conveyance } \\
\text { vehicle for trip }\end{array}$ & Sea state 4 \\
\hline 5 & & $\begin{array}{l}\text { Pilot conveyance vehicle to } \\
\text { destination base }\end{array}$ & Sea state 4 \\
\hline 6 & & $\begin{array}{l}\text { Open the conveyance } \\
\text { 'vehicle' to enable } \\
\text { unloading }\end{array}$ & Sea state 4 \\
\hline 7 & & $\begin{array}{l}\text { Unload the cargo from the } \\
\text { conveyance 'vehicle' }\end{array}$ & Sea state 4 \\
\hline$\ldots$ & $\cdots$ & & $\cdots$ \\
\hline
\end{tabular}

Table 7. Itemization of action sets demanded by each scenario and the conditions sets under which the actions are required.

Our plan is to continue this work with further development of methods to identify which of the tasks, the atomized elements of a sequence of actions which describe the performance of a system action, the activity associated with a scenario, need to be developed in order to derive the requirements that enable definition of the system. The challenge in the planned work is to determine which tasks, performed under which conditions, delineate the limiting conditions for the system, and therefore become the constraining actor associated with system design.

This paper has described the basic method. The next stage of this development is development of an example which demonstrates the method being applied to a realistic set-piece example in order to demonstrate how the method would be applied and to enable investigation of the benefit of the method with respect to reduction of the scenario analysis effort required.

\section{References}

Bodker, S. 2000. Scenarios in user-centred design—setting the stage for reflection and action. Interacting with Computers.13. pp. 61-75 
Bradfield, R., Wright, G., Burt, G., Cairns, G. and Van Der Heijden, K., 2005. The origins and evolution of scenario techniques in long range business planning. Futures, 37(8), pp.795-812.

Blythe, M.A., Wright, P.C. 2006. Pastiche scenarios: Fiction as a resource for user centred design. Interacting with Computers.18. pp. 1139-1164

Brooks jnr., F. 1987. No Silver Bullet: Essence and Accidents of Software Engineering. Computer. 1987. pp.10-19.

Carroll, J.M. 2000. Making Use: Scenario-based design of human-computer interactions. MIT PresS, Cambridge, MA.

Checkland, P., 1981. Systems thinking, systems practice. J. Wiley, Chichester Sussex, New York.

Chermack, T.J., 2004. Improving decision-making with scenario planning. Futures, 36(3), pp.295-309.

Clemons, E.K., 1995. Using scenario analysis to manage the strategic risks of reengineering. Sloan Management Review, 36(4), p.61.

Diaper, D., McKearney, S., Hurne, J. 1998. Integrating task and data flow analyses using the pentanalysis teqchnique. Ergonomics 41(11). pp.1553-1583

Diaper, D. 2001. Task analysis for knowledge descriptions (TAKD): A requiem for a method. Behaviour and Information Technology 20(3). pp.199-212

Eshach, H. and Bitterman, H., 2003. From Case-based Reasoning to Problem-based Learning. Academic Medicine, 78(5), pp.491-496.

Growe-Kuska, N., Heitsch, H. and Romisch, W., 2003, June. Scenario reduction and scenario tree construction for power management problems. In Power Tech Conference Proceedings, 2003 IEEE Bologna (Vol. 3, pp. 7-pp). IEEE.

Hmelo-Silver, C.E., 2004. Problem-based learning: What and how do students learn?. Educational psychology review, 16(3), pp.235-266.

Hsia, P., Samuel, J., Gao, J., Kung, D., Toyoshima, Y. and Chen, C., 1994. Formal approach to scenario analysis. IEEE Software, 11(2), p.33.

Huss, W.R. 1988. A move toward scenario analysis. International Journal of Forecasting. 4. pp.377-388

Jackson, S., Cook, S.C., Ferris, T.L.J. (2015) A generic state-machine model of system resilience, INCOSE Insight, 18(1), April, pp 14-18.

Kahneman, D., and Tversky, A. 1982. The simulation heuristic, in: Kahneman et al eds Judgement under uncertainty, heuristics and biases. Cambridge University Press, Cambridge, UK. pp.201-208

Kalbar, P.P., Karmakar, S. and Asolekar, S.R., 2012. Selection of an appropriate wastewater treatment technology: A scenario-based multiple-attribute decision-making approach. Journal of environmental management, 113, pp.158-169.

Liesiö, J. and Salo, A., 2012. Scenario-based portfolio selection of investment projects with incomplete probability and utility information. European Journal of Operational Research, 217(1), pp.162-172.

Ogilvy, J.A,. and Mancle, T. 1984. How to Construct and Use Scenarios. SRI International, Menlo Park, $C A$.

Porter, A.L, Roper, T.A., Mason, T.M., Rossini, F.A., Banks, J., Wiederholt, B.J. 1991. Forecasting and Management of Technology, John Wiley \& Sons Inc., New York. pp. 94-97 and 259-271. 
Postma, T.J. and Liebl, F., 2005. How to improve scenario analysis as a strategic management tool?. Technological Forecasting and Social Change, 72(2), pp.161-173.

Schoemaker, P.J., 1995. Scenario planning: a tool for strategic thinking. Sloan management review, 36(2), p.25-40.

Shin, K., Shin, Y., Kwon, J.H. and Kang, S.H., 2012. Risk propagation based dynamic transportation route finding mechanism. Industrial Management \& Data Systems, 112(1), pp.102-124.

Thistlethwaite, J.E., Davies, D., Ekeocha, S., Kidd, J.M., MacDougall, C., Matthews, P., Purkis, J. and Clay, D., 2012. The effectiveness of case-based learning in health professional education. A BEME systematic review: BEME Guide No. 23. Medical teacher, 34(6), pp.421-444.

Tompkins, E.L., Few, R. and Brown, K., 2008. Scenario-based stakeholder engagement: incorporating stakeholders preferences into coastal planning for climate change. Journal of environmental management, 88(4), pp.1580-1592.

Wang, M.Y. and Lan, W.T., 2007. Combined forecast process: Combining scenario analysis with the technological substitution model. Technological Forecasting and Social Change, 74(3), pp.357-378.

Yacoub, S.M., Cukic, B. and Ammar, H.H., 1999. Scenario-based reliability analysis of component-based software. In Software Reliability Engineering, 1999. Proceedings. 10th International Symposium on (pp. 22-31). IEEE.

\section{Biography}

Timothy L.J. Ferris is a Senior Lecturer in the Centre for Systems Engineering, Cranfield University, Defence Academy of the United Kingdom Shrivenham, SN6 8LA, UK. Tim has 20 years of experience teaching and researching SE at Cranfield University and formerly at University of South Australia. He was a member of the BKCASE project team.

Stephen Barker is a lecturer in Systems Engineering for Defence Capability at Cranfield University. Steve has many years' experience of working in the fields of Systems thinking and Systems engineering within both the Defence and the Commercial sectors. He is currently responsible for teaching at MSc level, managing a number of modules, and has also been Course Director for a major suite of SE-related short courses. 